\title{
O consenso entre as vozes dialógicas das DCNs para o uso das tecnologias digitais na formação docente
}

\author{
The consensus among the dialogical voices of the national \\ curricular guidelines for the use of digital technologies in \\ teacher training
}

El consenso entre las voces dialógicas de las DCNs para el uso de tecnologías digitales en la formación docente Camila de Araújo Beraldo Ludovice ${ }^{1}$, Terezinha Gorete Vilela Soares²

\begin{abstract}
RESUMO: Esta pesquisa tem como objetivo investigar como se dá a formação do docente no que se refere ao trabalho com as tecnologias digitais e propor alguns princípios para uma proposta de ensino dessas tecnologias à luz das reflexões de Bakhtin e seu Círculo. Para isso, concentra-se na caracterização de um documento oficial normativo como um gênero do discurso e na verificação do modo como se travam nele as relações dialógicas para o tema apresentado. Sua metodologia é de cunho qualitativo e bibliográfico. Nossa investigação orientou-se pela perspectiva metodológica de Bakhtin e de seu Círculo, amparada na concepção ampla de enunciados, gêneros discursivos, esferas e dialogismo, bem como nos trabalhos de seus comentadores, tais como: Faraco (2009), Brait (2005, 2016), Grillo (2016), Marchezan (2016) e Fiorin (2017). Constatou-se que o discurso da Resolução reflete e refrata a voz de uma alta esfera pública educacional (MEC/CNE/CP), assim como, circula e é consumido nas esferas educacionais de formação docente e escolar. As vozes dos autores são de sujeitos ativos no discurso, que ao enunciar, se direcionam aos seus interlocutores, que são as Instituições de Ensino Superior (IES), e aos sujeitos em formação docente e escolar. O contexto enunciativo da Resolução CNE/CP 2/2015 assume 0 papel de formar docentes para uma educação de qualidade $e$ contemporânea, pois existe em diversos pontos do enunciado a preocupação por parte dos enunciadores sobre a implantação dos recursos das tecnologias digitais nos ambientes de formação.
\end{abstract}

\footnotetext{
${ }^{1}$ Docente permanente do Programa de Pós-graduação em Linguística (Mestrado e Doutorado) da Universidade de Franca - UNIFRAN. E-mail: camilaludovice@gmail.com

${ }^{2}$ Mestre em Linguística pela Universidade de Franca - UNIFRAN. E-mail: goretevilela@hotmail.com
} 
PALAVRAS-CHAVE: Bakhtin. Tecnologias digitais. Gênero do discurso normativo. Relações dialógicas. Formação docente.

ABSTRACT: The current research aims to investigate how teacher training takes place in terms of digital technologies works and to propose some principles for a teaching proposal for these technologies in the light of the reflections of Bakhtin and his Circle. For this, it focuses on the characterization of an official normative document as a discourse genre and on the verification of the way in which dialogical relations are interwoven with the presented theme. It has a qualitative and bibliographic methodology. Our investigation was guided by the methodological perspective of Bakhtin and his Circle, supported by the broad conception of statements, discourse genres, spheres, and dialogism, as well as in the works of his commentators, such as: Faraco (2009), Brait (2005, 2016 ), Grillo (2016), Marchezan (2016), and Fiorin (2017). It was found that the Resolution's speech reflects on and refracts the voice of a high educational public sphere (MEC/CNE/CP), as well as it circulates and is consumed in the educational spheres of teacher and school training. The authors' voices are those of active subjects in the discourse, who, when enunciating, address themselves to their interlocutors, which are the Higher Education Institutions (HEIs), and to the subjects undergoing teaching and school training. The enunciative context of the Resolution $\mathrm{CNE} / \mathrm{CP} 2 / 2015$ assumes the role of training teachers for quality and contemporary education, since there are several points in the statement about the enunciators' concern about the implementation of digital technology resources in training environments.

KEYWORDS: Bakhtin. Digital technologies. Normative discourse gender. Dialogical relations. Teacher training.

RESUMEM: Esta investigación tiene como objetivo analizar cómo ocurre la formación del profesor en el ámbito de trabajo con tecnologías digitales y proponer algunas bases para una propuesta de enseñanza de estas tecnologías a la luz de las reflexiones de Bakhtin y su Círculo. Para esto se centra en la caracterización de un documento normativo oficial como un género de discurso y en la verificación del modo en que se establecen las relaciones dialógicas para el tema presentado. Su metodología es de cuño cualitativo y bibliográfico. Nuestra investigación se orientó por la perspectiva metodológica de Bakhtin y su Círculo, respaldada por la amplia concepción de los enunciados, los géneros del discurso, las esferas y el diálogo, así como en los trabajos de sus comentaristas, tales como: Faraco (2009), Brait (2005, 2016), Grillo (2016), Marchezan (2016) y Fiorin (2017). Se comprobó que el discurso de la Resolución refleja y refracta la voz de una esfera pública de alta educación (MEC / CNE / CP), así como también circula y se consume en las esferas educativas de la formación docente y escolar. Las voces de los autores son de los sujetos activos en el discurso, quienes, al enunciar, se dirigen a sus interlocutores, que son las instituciones de educación superior (IES), y a los sujetos en formación docente y escolar. El contexto enunciativo de la Resolución CNE / CP 2/2015 asume el papel de capacitar a los docentes para la educación de calidad y contemporánea, ya que hay varios puntos en la declaración de que los enunciadores están preocupados al respecto de la implementación de recursos de tecnología digital en los ambientes de formación.

PALABRAS CLAVE: Bakhtin. Tecnologías digitales. Discurso normativo género. Relaciones dialógicas. Formación del profesorado. 


\section{Considerações Iniciais}

Esta investigação tem como foco a formação do professor no uso das tecnologias digitais no contexto educacional. Esse tema é um convite à reflexão sobre o ambiente escolar de aprendizagem ocupado por alunos com os seus celulares e submersos nas mídias digitais, comunicando-se entre si e acessando diversas informações, e pelo professor, presente e responsável pela mediação dos conhecimentos.

Nesse contexto, a centralidade que os professores ocupam nos espaços do conhecimento solicita novas atitudes e modos de encaminhamento da busca de conhecimento dos alunos por meio das tecnologias digitais. Nossa hipótese de base contém a ideia de que o professor, como agente ativo, deve ser 0 primeiro a se preparar para saber atuar diante de tantas mudanças trazidas pelas tecnologias digitais na atualidade.

A escola encontra-se em uma encruzilhada entre o ensino tradicional e a ampliação das habilidades dos alunos no uso dos meios tecnológicos, das mídias e das comunicações, ficando com a responsabilidade de monitorar os desdobramentos que a tecnologia digital provoca, assumindo a verificação do que é pertinente ou não para o ensino e a aprendizagem. Assim, justifica-se a pesquisa sobre o modo como se dá orientação oficial por meio de resoluções e a formação do docente para o uso dos recursos tecnológicos no ensino.

Dessa forma, a incorporação dos recursos tecnológicos no processo de formação dos professores torna-se necessária, uma vez que estamos no meio de uma convergência tecnológica digital e se percebe que muitos deles não fazem uso desses recursos, ainda não recebem instruções adequadas sobre seu uso. Esses recursos representam uma constante na vida em sociedade, propagando informação, divulgando conhecimentos científicos e a escola nem sempre está preparada para possibilitar aos alunos condições de ampliar as habilidades para o uso desses meios.

Nosso objeto de estudo constitui-se da análise da Resolução CNE/CP no 2/2015, de $1^{0}$ de julho de 2015, produzido e aprovado pelo Conselho Pleno 
(CP) do Conselho Nacional de Educação (CNE) em consonância com o Ministério da Educação (MEC), que define as Diretrizes Curriculares Nacionais (DCNs) para a formação inicial docente em nível superior e o uso das tecnologias digitais. A citada Resolução é direcionada para a organização dos cursos de graduação em licenciatura, formação pedagógica para graduados não licenciados e segunda licenciatura. Além de normatizadoras e reguladoras da formação docente, as (DCNs) dimensionam também a expectativa social e ideológica acerca do que se espera do profissional docente, o egresso do curso de formação docente.

As (DCNs) consideram que a consolidação das normas nacionais para a formação docente é indispensável para o projeto nacional da educação brasileira; a concepção sobre conhecimento, educação e ensino é basilar; a preparação profissional docente requer aprendizagem autônoma e contínua ao longo da vida; e que o currículo de formação é o conjunto de valores que contribui para a construção e o desenvolvimento do aprendizado.

Esta Resolução apresenta uma estreita relação entre os sujeitos por meio do diálogo promovido pela enunciação, um ponto de tensão entre as vozes do Conselho Nacional de Educação (CNE), as Instituições de Ensino Superior (IES) e os sujeitos em formação acadêmica e escolar.

Nesse contexto, esta pesquisa tem como objetivo investigar como se dá a formação do docente no que se refere ao trabalho com as tecnologias digitais e propor alguns princípios para uma proposta de ensino dessas tecnologias à luz das reflexões de Bakhtin e seu Círculo. Para isso, concentra-se na caracterização de um documento oficial normativo como um gênero do discurso e na verificação do modo como se travam nele as relações dialógicas para o tema proposto.

O objetivo específico está em descobrir como acontece a formação do docente para o uso das tecnologias digitais e os modos de uso destas nas ações pedagógicas. Para isso, serão analisados trechos da Resolução na tentativa de mostrar as relações dialógicas estabelecidas a partir dos seus enunciados concretos com a esfera de atividade da educação, pois na Resolução ecoam 
vozes oficiais e sociais da educação brasileira, as quais são autorais e ideologicamente marcadas, o seu discurso direciona-se às comunidades acadêmica e escolar. Há, portanto, uma vinculação de vozes, (IES), estados, escolas, alunos, famílias e professores.

\section{Metodologia}

Esta pesquisa é de cunho qualitativo, bibliográfico e analítico, sendo que investigamos, primeiramente, toda a bibliografia referente aos gêneros do discurso e às relações dialógicas em Bakhtin, seu Círculo e seus comentadores e, simultaneamente, encaminhamos uma análise do documento normativo, em busca de sua compreensão como gênero discursivo e da forma como dialoga com a comunidade docente e escolar que trabalha com as tecnologias digitais.

Com a finalidade de analisar esse tema, foram realizadas leituras e um levantamento bibliográfico sobre os assuntos em diversos livros, teses, dissertações e artigos, entre os anos de 2013 e 2018, em bibliotecas virtuais, a partir das palavras-chave: Bakhtin, formação inicial docente e tecnologias digitais, gênero do discurso; dialogismo, relações dialógicas e esferas.

A partir de um percurso metodológico que toma como ponto de partida a análise de trechos dos textos que constituem gêneros da esfera jurídiconormativa, analisaremos a constituição da Resolução CNE/CP n 2/2015 na sua dimensão global. Nosso propósito é verificar como esse texto se organiza como gênero e qual é o conjunto de valores que preside a sua organização.

Bakhtin (2011) sugere que não analisemos, de fato, o dialogismo, mas, sim, os fios dialógicos vivos e presentes em um discurso. Para ele, o enunciado gera uma resposta e precede outra resposta, isto se dá na forma de compreensão e atitude responsiva ativa, sendo assim, não se chega a uma única conclusão, mas a possíveis compreensões acerca do que se propõe fazer.

Dentro da perspectiva bakhtiniana, não há uma teoria específica para a análise dialógica de um discurso, ou seja, não existe uma metodologia de análise rígida. Brait (2016) cita que, nas contribuições de Bakhtin sobre a 
análise dialógica de um objeto, ele não configura a análise como uma proposta fechada e linearmente organizada, pronta e acabada para a análise, mas deixa "um corpo de conceitos, noções e categorias que especificam uma postura dialógica diante do corpus discursivo, da metodologia e do pesquisador" (BRAIT, 2016, p. 29).

Sendo assim, Marchezan (2016, p. 129) afirma que "o diálogo instrui a perspectiva de análise, ao mesmo tempo que nomeia seu próprio objeto" de forma a auxiliar o estudioso da linguagem. Sendo que, para ela "o esforço do diálogo do estudioso com o texto é, então, de se aproximar, compreender as forças vivas de que surge e em que atua, de vivenciá-las, para, depois [...] examinar o texto de fora, com a visão de um todo". (MARCHEZAN, 2016, p. 129).

Nesta perspectiva, uma análise dialógica adequada é possível a partir de observações que levem em conta o material linguístico e as suas ramificações. Brait (2016) nos diz que, para o entendimento do discurso em uma perspectiva dialógica, necessita-se de um olhar particular para as práticas discursivas, levando-se em conta os contextos linguísticos e os mais amplos, os extralinguísticos, isto quer dizer que uma análise dialógica deverá ultrapassar a materialidade linguística em que o discurso se insere.

Esta investigação pretende analisar, na perspectiva bakhtiniana, a Resolução CNE/CP n 2/2015, que é um documento oficial normativo, em busca de caracterizá-lo como gênero do discurso e de verificar o modo como se dão, nele, as relações dialógicas e as Diretrizes curriculares nacionais (DCNs) que emanam desse documento e tratam do uso responsável das tecnologias digitais nas esferas de formação acadêmica e escolar. Com vistas a estabelecer uma análise dialógica sobre a constituição do documento, seguiremos o percurso que se estabelece desde as esferas de abrangência, as condições de produção, a constituição das vozes dos sujeitos envolvidos nos processos dialógicos e o que emerge do discurso educacional para o tema proposto.

Nosso objeto de estudo constitui-se da análise de trechos da Resolução CNE/CP no 2/2015, de $1^{0}$ de julho de 2015 , produzida e aprovada pelo 
Conselho Pleno do Conselho Nacional de Educação (CNE) em consonância com o Ministério da Educação (MEC), que define as Diretrizes Curriculares Nacionais (DCNs) para a formação inicial docente em nível superior e o uso das tecnologias digitais.

A estrutura enunciativa da Resolução CNE/CP no 2/2015 é composta por 25 artigos e organizada em dezesseis páginas. Ela possui uma introdução composta pela apresentação do documento e por algumas considerações sobre a educação brasileira. Na sequência, está apresentada a divisão dos capítulos: "Das disposições gerais; Formação dos profissionais do magistério para educação básica: Base Comum Nacional"; "Do(a) egresso(a) da formação inicial e continuada"; "Da formação inicial do magistério da educação básica em nível superior"; "Da formação inicial do magistério da educação básica em nível superior: Estrutura e currículo"; "Da formação continuada dos profissionais do magistério"; "Dos profissionais do magistério e sua valorização"; e "Das disposições transitórias" (CONSELHO NACIONAL DE EDUCAÇÃO, 2015).

Os trechos selecionados e analisados poderão elucidar como os sujeitosenunciadores (falantes) do discurso da Resolução consolidam os seus posicionamentos e se dirigem a um interlocutor (ouvinte) direto na interação discursiva. Assim, o dizer está internamente orientado e o núcleo tem a intenção de obter reações daquele para quem foi elaborado, o interlocutor, o qual, ao compreender os significados, ocupa posição responsiva e se torna respondente.

\section{Fundamentação Teórica}

A fundamentação teórica baseia-se nas reflexões de Bakhtin (2011) e de seu Círculo, bem como nos trabalhos de seus comentadores, tais como Faraco (2009), Brait (2005, 2016), Grillo (2016), Marchezan (2016) e Fiorin (2017), entre outros autores estudiosos do filósofo.

A linguística defendida por Bakhtin é considerada uma translinguística porque ultrapassa a visão de língua como sistema. Para esse autor, não se 
pode entender a língua isoladamente, devem-se observar os sentidos de uma enunciação. É preciso considerar os fatores extralinguísticos nas análises, como o contexto da situação de comunicação (da fala, a relação do falante com o ouvinte) e o contexto social no sentido amplo (dimensão social, momento histórico e socioideológico). Ao se apropriar de determinado enunciado, o sujeito leitor (interlocutor) se torna sujeito ativo responsivo, pois ao compreendê-lo, se posiciona em relação a ele em um processo ativo.

Destarte, o ponto de partida na teoria dos gêneros é o vínculo que existe entre 0 uso da linguagem e as atividades humanas. Essas atividades se realizam em esferas diversificadas e infinitas, cada campo de utilização da língua elabora os seus tipos de enunciados, ou seja, não há como produzir enunciados fora de uma esfera de ação. Segundo Fiorin (2017, p. 68):

\begin{abstract}
Não se produzem enunciados fora das esferas de ação, o que significa que eles são determinados pelas condições específicas e pelas finalidades de cada esfera. Essas esferas de ação ocasionam o aparecimento de certos tipos de enunciados, que se estabilizam precariamente e que mudam em função de alterações nessas esferas de atividades.
\end{abstract}

Esfera ou campo é o conceito que Bakhtin (2011) utiliza para nomear os ambientes em que os discursos são produzidos, entram em circulação e são recepcionados. Ele estabelece que o sujeito enuncia a partir de uma dada esfera ou campo da atividade humana, e que a noção de esfera, facilita a compreensão da natureza e da classificação do gênero. Fiorin (2017) nos fornece alguns exemplos de esferas: familiar, acadêmica, tecnológica, publicitária, literária, cotidiana, escolar, religiosa, jornalística, jurídica, científica, didática, comercial, pessoal, de entretenimento, íntima, entre muitas outras existentes. Grillo (2016) afirma que a noção de esfera está presente em toda a obra de Bakhtin e que os seus conceitos revelam uma atenção à diversidade das manifestações culturais humanas. Isso se constitui como uma alternativa para pensarmos as especificidades das produções ideológicas e para compreendermos a origem e a classificação dos gêneros. 
O conceito de esfera contempla uma situação específica de dizer, o tempo e lugar histórico (cronotopo na perspectiva bakhtiniana), os participantes da enunciação, as possibilidades de relações sociais e um leque de conteúdos temáticos possíveis.

Sendo assim, a esfera define maneiras de dizer e enunciar. O filósofo, considera que o enunciado é uma unidade da comunicação discursiva, que pode ser falado ou escrito, pressupõe-se como ato da comunicação social, é uma unidade real de um discurso, e é, ainda, um elemento expressivo que mostra a relação subjetiva, emocional e valorativa do falante com o conteúdo de um objeto e do sentido do seu enunciado.

$\mathrm{Na}$ teoria bakhtiniana, toda enunciação faz parte de um gênero discursivo, e um gênero se define pelo seu propósito comunicativo e forma linguística, é na dialogia do enunciado que estão inseridos os gêneros dos discursos, isto é possível perceber pela temática, composição e estilo da enunciação. Portanto, só nos comunicamos, falamos e escrevemos por meio de gêneros do discurso. Logo, não há comunicação sem a formação de um gênero discursivo. Até mesmo nos simples diálogos entre amigos, o discurso é organizado com o intuito de prover a comunicação clara e objetiva, ou seja, repassar a ideia do falante. Em outras palavras, a enunciação é moldada pelos gêneros discursivos:

\footnotetext{
Nós aprendemos a moldar o nosso discurso em formas de gênero e, quando ouvimos o discurso alheio, já adivinhamos o seu gênero pelas primeiras palavras, adivinhamos um determinado volume (isto é, uma extensão aproximada do conjunto do discurso), uma determinada construção composicional, prevemos o fim, isto é, desde o início temos a sensação do conjunto do discurso que em seguida apenas se diferencia no processo de fala (BAKHTIN, 2011, p. 283).
}

Os gêneros discursivos incluem a variedade de diálogos do cotidiano e também enunciados da vida social, pública, institucional, artística, filosófica, etc. Dessa maneira, são concebidos com finalidades comunicativas e expressivas de interação, manifestações e lutas com os nossos pensamentos. Nas palavras de Bakhtin (2011, p. 298): 
O enunciado é pleno de tonalidades dialógicas, e sem levá-las em conta é impossível entender até o fim o estilo de um enunciado. Porque a nossa própria ideia - seja filosófica, científica, artística nasce e se forma no processo de interação e luta com os pensamentos dos outros, e isso não pode deixar de encontrar o seu reflexo também nas formas de expressão verbalizada do nosso pensamento.

Para Bakhtin (2011), o trabalho com a língua opera através de enunciados concretos em seu aspecto expressivo, assim, o estilo está indissoluvelmente ligado ao enunciado e aos gêneros do discurso. O enunciado se manifesta por estilos e são correias de transmissão entre a historicidade da sociedade e linguagem.

Nota-se, dessa forma, que a riqueza e a diversidade dos gêneros discursivos são infinitas e respeitam as questões ideológicas de cada época, os efeitos de sentido discursivo, as vozes e as apreciações de valor que o sujeito do discurso faz, cabendo novas interpretações em cada nova atividade humana. Conforme Bakhtin (2011, p. 294) "em cada época, em cada círculo social, em cada micromundo familiar, de amigos e conhecidos, de colegas, em que o homem cresce e vive, sempre existem enunciados investidos de autoridade que dão o tom".

Mikhail Bakhtin define o dialogismo como o permanente diálogo existente entre os diferentes discursos, o processo de interação interdiscursivo da linguagem, que ocorre tanto na escrita como na leitura, pois o texto não é visto isoladamente, mas, sim, correlacionado com outros discursos similares ou próximos. Assim, o dialogismo se manifesta nas relações que se estabelecem entre o eu e o outro, nas diversas vozes presentes em um mesmo discurso e nas relações de vozes de um discurso com outro, é, portanto, resultante de um enfrentamento de vozes. Brait (2005, p. 94-95) ressalta que,

Por um lado, o dialogismo diz respeito ao permanente diálogo, nem sempre simétrico e harmonioso, existente entre os diferentes discursos que configuram uma comunidade, uma cultura, uma sociedade. É nesse sentido que podemos interpretar o dialogismo como o elemento que instaura a constitutiva natureza interdiscursiva da linguagem. Por outro lado, o dialogismo diz respeito às relações que se estabelecem entre o eu e o outro nos processos discursivos 
instaurados historicamente pelos sujeitos, que, por sua vez, se instauram e são instaurados por esses discursos.

De certa forma, o termo dialogismo está em uma perspectiva mais voltada para o produto da enunciação, nas relações das vozes e nos atos da comunicação dialógica. Conforme Marchezan (2016), o diálogo, na relação com o gênero, torna-se um conceito fomentador e organizador de uma reflexão, por consequência, o próprio conceito de gênero é caracterizado com base no diálogo.

É a partir do diálogo do contexto enunciativo que se estabelecem as relações dialógicas com as vozes mais próximas e as mais distantes, as quais são entendidas por Bakhtin como relações dialógicas no pequeno e no grande tempo, pois, para ele, não existem limites e nada está absolutamente morto, uma vez que as formas podem ser renovadas e, consequentemente, estabelecer novos contextos. Para o filósofo Bakhtin (2011, p. 401), "o texto só tem vida contatando com outro texto (contexto). Só no ponto desse contato de texto eclode a luz que ilumina retrospectiva e prospectivamente, iniciando dado texto no diálogo".

Os efeitos de sentidos são encontrados nas manifestações reais da língua no interior de uma enunciação. Sendo assim, as categorias linguísticas ganham sentido e identidade no conjunto da enunciação. Conforme Fiorin (2017, p. 22) "Todo discurso que fale de qualquer objeto não está voltado para a realidade em si, mas para os discursos que a circundam".

Faraco (2009) comenta que Bakhtin caracteriza as relações dialógicas como relações de sentido que se estabelecem entre enunciados ou mesmo no seu interior, fazendo referência à interação verbal, e não visa apenas ao evento face a face, mas também à dialogização interna do discurso.

Para Bakhtin (2011) onde há enunciado, há relação dialógica, pois nele tem sujeito enunciador, interlocutor (que pode ser o enunciador) e um contexto de vozes sociais e individuais emoldurado, e é a partir dessas múltiplas vozes que essas relações se constituem. Segundo Fiorin (2017, p. 31) "os fenômenos 
presentes na comunicação real podem ser analisados à luz das relações dialógicas que os constituem".

Segundo o filósofo, para que ocorram relações dialógicas, é preciso que qualquer material linguístico tenha entrado na esfera do discurso, seja um enunciado, isto é, ganhe autor, materialize-se, torne-se concreto, assuma uma posição social, permita réplicas e a busca de sentido, suscite respostas e confrontos ao dito e acolha a palavra do outro para confirmá-la ou rejeitá-la, permitindo, dessa maneira, a geração de uma significação responsiva. (BAKHTIN, 2011).

O filósofo russo esclarece que as relações dialógicas são possíveis entre enunciados integrais, e também em uma palavra isolada se nela chocar dialogicamente duas vozes, isto é, se uma representar partes significantes de outra voz. Sendo assim, as relações dialógicas são bem mais amplas que o diálogo no sentido restrito, por isso, pode ocorrer em relação ao todo do enunciado, em partes separadas e em relação a uma só palavra do seu interior. Dessa forma, Bakhtin (2011, p. 327) afirma que "A relação com o sentido é sempre dialógica. A própria compreensão é dialógica".

Dessa forma, uma análise dialógica adequada é possível a partir de observações que levem em conta o material linguístico e as suas ramificações. Brait (2016) nos diz que, para o entendimento do discurso em uma perspectiva dialógica, é necessário um olhar particular para as práticas discursivas, levandose em conta os contextos linguísticos e os mais amplos, os extralinguísticos. Sendo assim, a dialogia é o confronto do entoamento e dos sistemas de valores que posicionam as visões de mundo em determinado campo de visão.

\section{Análise do Objeto de Estudo}

Ao analisarmos esta Resolução, partimos do pressuposto bakhtiniano, de que ela é um enunciado, faz parte de um gênero discursivo e de uma esfera da atividade humana, pois ao se tornar enunciado, ganha relativa conclusibilidade, 
há em seu contexto objetivos determinados, isto é, posicionamentos de valores do autor no texto perante uma ideia definida.

Ao considerar as reflexões bakhtinianas, a Resolução CNE/CP nº 2/2015 enquadra-se no gênero do discurso normativo, com todas as características de um gênero secundário (BAKHTIN, 2011, p. 263). Trata-se de um documento oficial normativo que possui funções deliberativas e normativas. Segundo 0 dicionário Aurélio da Língua Portuguesa, Resolução significa "ato ou efeito de resolver-se", "decisão, deliberação", isso é, tem potencial para deliberar (RESOLUÇÃO..., 1988, p. 566). Conforme corrobora a posição de Cury (2006, p. 43),

A resolução é um ato normativo emanado de autoridade específica do poder executivo com competência em determinada matéria regulando-a com fundamento em lei. O Conselho Nacional de Educação, por lei, é um órgão com poderes específicos para expedir uma resolução.

Dessa forma, essa Resolução tem funções regulatórias emanadas de um órgão oficial público destinado a disciplinar determinado assunto educacional de interesse próprio. Portanto, espera-se que o interlocutor envolvido tome conhecimento acerca do enunciado, aja em conformidade com o conteúdo prescrito e se revista de vigilância para fazer cumprir uma determinação, estabelecendo uma relação de cumplicidade entre autores e interlocutores no cumprimento das normas estabelecidas.

O Conselho Nacional de Educação (CNE) e o seu Conselho Pleno (CP), em consonância com o Ministério da Educação (MEC), são os responsáveis pela produção discursiva dos enunciados das DCNs, conforme descrição contida no início da Resolução CNE/CP 02/2015:

\author{
MINISTÉRIO DA EDUCAÇÃO \\ CONSELHO NACIONAL DE EDUCAÇÃO \\ CONSELHO PLENO \\ [...] O Presidente do Conselho Nacional de Educação, no uso de suas \\ atribuições legais e tendo em vista o disposto na Lei no 9.131, de 24 \\ de novembro de 1995 [...] homologado por Despacho do Ministro de
}


Estado da Educação publicado no Diário Oficial da União de 25 de junho de 2015. (CONSELHO NACIONAL DE EDUCAÇÃO, 2015, p. 1).

Nas considerações iniciais da Resolução CNE/CP no 2/2015, estão expressas as consolidações das normas nacionais para a formação profissional docente:

\begin{abstract}
A consolidação das normas nacionais para a formação de profissionais do magistério para a educação básica é indispensável para o projeto nacional da educação brasileira [...]. A concepção sobre conhecimento, educação e ensino é basilar para garantir o projeto da educação nacional [...]. A igualdade de condições para o acesso e a permanência na escola [...] constituem princípios vitais para a melhoria e democratização da gestão e do ensino. [...] a docência como ação educativa e como processo pedagógico intencional e metódico (CONSELHO NACIONAL DE EDUCAÇÃO, 2015, p. 2).
\end{abstract}

Esse tipo de discurso é considerado autoritário, o que é comum nos documentos oficiais pelo princípio prescritivo, pois remete à voz de uma alta esfera pública. Assim, é um discurso que provoca reações, tensões e embates pelas palavras interiormente persuasivas e pelo viés pedagógico que o constitui, pois apresenta um novo documento norteador e organizador de ensino. Com base nisso, a Resolução instaura novas possibilidades e novos pontos de vista, os quais causam reação-resposta nos seus interlocutores.

Em síntese, é um tipo de enunciação que não se fecha em si mesmo, tem objetivo determinado, revela, no seu contexto, acentos de valor e de apreciação de sentido, possui elementos com especificidades discursivas, tem posições assumidas e sofre influências conforme os momentos sócio-históricos de produção e responde a outros decretos, resoluções e portarias, tal como exemplifica o trecho a seguir:

[...] considerando o Decreto no 6.755, de 29 de janeiro de 2009, as Resoluções CNE/CP no 1, de 18 de fevereiro de 2002, CNE/CP no 2, de 19 de fevereiro de 2002, CNE/CP no 1, de 15 de maio de 2006, CNE/CP no 1, de 11 de fevereiro de 2009, CNE/CP no 3, de 15 de junho de 2012, e as Resoluções CNE/CEB no 2, de 19 de abril de 1999, e CNE/CEB no 2, de 25 de fevereiro de 2009, as Diretrizes Curriculares Nacionais da Educação Básica, bem como o Parecer CNE/CP no 2, de 9 de junho de 2015, homologado por Despacho do Ministro de Estado da Educação publicado no Diário Oficial do União 
de 25 de junho de 2015 (CONSELHO NACIONAL DE EDUCAÇÃO, 2015 , p. 2).

Como se trata de um enunciado oficial, é investido de autoridade, tem tom valorativo porque não é neutro, tem ideologia, remete a posições axiológicas e impõe sentidos. Não há possibilidade de neutralidade na sua constituição nem a criação de reações passivas. Assim, é uma instância de produção de sentidos na medida em que se cerca de parâmetros normatizadores e dialógicos para o contexto da formação docente.

\section{As vozes dialógicas da Resolução}

Esta Resolução apresenta uma estreita relação entre os sujeitos, por meio do diálogo promovido pela enunciação, um ponto de tensão entre as vozes do eu e do outro, contexto de voz de um autor para os seus interlocutores.

A produção dessa Resolução é traçada no âmbito nacional pelos autores (MEC), (CNE) e (CP), liderada pela União e formulada com a participação de sujeitos interessados no contexto educacional de formação. Portanto, o seu conteúdo reflete e refrata o universo ideológico e social de esferas públicas educacionais. Dessa forma, a sua formulação se constitui em situação de apoio mútuo, pois a política nacional de formação de professores ancora-se em consensos construídos com os organismos normativos educacionais, existindo a cooperação e a colaboração de outros entes federativos e instituições, conforme descrito nas (DCNs):

A colaboração constante entre os entes federados na consecução dos objetivos da Política Nacional de Formação de Profissionais do Magistério da Educação Básica, articulada entre o Ministério da Educação (MEC), as instituições formadoras e os sistemas e redes de ensino e suas instituições. (CONSELHO NACIONAL DE EDUCAÇÃO, 2015, p. 4). 
Dentro dessa perspectiva, fica evidente que a produção da Resolução é consenso de vozes coletivas que criam e sustentam o discurso do documento. As principais vozes produtoras do discurso são as das esferas públicas educacionais - do (MEC), (CNE) e de seu Conselho Pleno -, mas é possível perceber que há consonância com outras vozes indiretas, como as de níveis políticos, econômicos, governamentais, educacionais e técnico-científicos, pois o discurso faz parte de uma esfera pública educacional e a sua produção depende de outras reflexões e de elos com as legislações pertinentes em vigor, havendo, portanto, outras vozes que aderem ao discurso, assim como há outras esferas inseridas no discurso da Resolução:

"CONSIDERANDO a necessidade de articular as Diretrizes Curriculares Nacionais para a Formação Inicial e Continuada, em Nível Superior, e as Diretrizes Curriculares Nacionais para a Educação Básica;" (CONSELHO NACIONAL DE EDUCAÇÃO, 2015, p. 3).

Nota-se que a estrutura da Resolução é resultante da diversidade de pensamentos, demandas e anseios de sujeitos envolvidos com a formação docente em um espaço de lutas entre vozes de sujeitos autores que colocam em movimento contextos, conviç̧ões, percepções, posições e intenções para prescrever e normatizar um tipo de ensino como compromisso público de Estado, sempre em conformidade com as concepções que as pautam, como, por exemplo, a de que a educação tem que ter um efetivo padrão de qualidade a partir de bases científicas e técnicas sólidas. Portanto, os autores da Resolução são sujeitos que the atribuem sentidos, posicionando-se e interagindo dentro de um universo de valores permeado por vozes que defendem as suas posições ideológicas, o que resulta em uma arena de debates discursivos, pois ocorrem muitos estudos e discussões até a sua formatação final:

Art. $1^{0}$ Ficam instituídas, por meio da presente Resolução, as Diretrizes Curriculares Nacionais para a Formação Inicial e Continuada em Nível Superior de Profissionais do Magistério para a Educação Básica, definindo princípios, fundamentos, dinâmica formativa e procedimentos a serem observados nas políticas, na gestão e nos 
programas e cursos de formação, bem como no planejamento, nos processos de avaliação e de regulação das instituições de educação que as ofertam. (CONSELHO NACIONAL DE EDUCAÇÃO, 2015, p. 2).

O discurso dessa Resolução está voltado para um interlocutor direto, representado pelos diversos segmentos das Instituições de Ensino Superior (IES) e pelos profissionais responsáveis pela criação e pela gestão dos cursos de formação docente, os quais não podem ser passivos, mas sujeitos ativos e responsivos, que ocupam lugares e papéis sociais específicos, conforme a situação que Ihes é outorgada. Para isso, adotam determinadas posturas de acordo com a situação concreta e real pela qual são orientados. São sujeitos que se reúnem para construir os projetos pedagógicos de formação e promover a implantação dos cursos nas (IES) mediante as orientações normativas das reformas educacionais definidas pelas (DCNs), sob o olhar de uma legislação vigente:

$\S 2^{\circ}$ As instituições de ensino superior devem conceber a formação inicial e continuada dos profissionais do magistério da educação básica na perspectiva do atendimento às políticas públicas de educação, às Diretrizes Curriculares Nacionais, ao padrão de qualidade e ao Sistema Nacional de Avaliação da Educação Superior (Sinaes), manifestando organicidade entre o seu Plano de Desenvolvimento Institucional (PDI), seu Projeto Pedagógico Institucional (PPI) e seu Projeto Pedagógico de Curso (PPC) como expressão de uma política articulada à educação básica, suas políticas e diretrizes. (CONSELHO NACIONAL DE EDUCAÇÃO, 2015, p. 3).

A Resolução traz um direcionamento para que as (IES) vinculem 0 conhecimento também às reais necessidades da população e ao meio social em que vivem os sujeitos egressos, pois considera que "a realidade concreta dos sujeitos que dão vida ao currículo deve ser contextualizada no espaço e no tempo e atentos às características [dos seus alunos]" (CONSELHO NACIONAL DE EDUCAÇÃO, 2015, p. 2).

Portanto, é nos atos de interlocução e formulação dos currículos e projetos da formação docente por equipes educacionais especializadas, que as relações dialógicas do enunciado estão estabelecidas e se cruzam 
dialogicamente, promovendo embates pela adesão acerca do que nele está prescrito, pois são os atos constitutivos da Resolução que potencializam essa construção por sujeitos interlocutores, que vão torná-lo mais próximo e possível de ser vivenciado pelos sujeitos em formação.

O discurso da Resolução tem como interlocutores indiretos os sujeitos em formação docente, ou seja, os egressos dos cursos, os quais se beneficiam dos projetos de formação e Ihes justificam a existência. Nesse contexto, são considerados ativos no processo de sua formação, porém não são sujeitos ativos do dizer, mas, na realidade, receptores do que é elaborado e executado pelas (IES).

As (DCNs) apontam, no artigo 70 , que o egresso deve possuir vasto repertório de informações e habilidades, e que o conhecimento deve ser bem "fundamentado em princípios de interdisciplinaridade, contextualização, democratização, pertinência e relevância social, ética e sensibilidade afetiva e estética [...]" (CONSELHO NACIONAL DE EDUCAÇÃO, 2015, p. 7). Isso implica a apropriação de conhecimento permeado por projeto formativo com sólida base teórica e interdisciplinar, passível de refletir "a especificidade da formação docente, assegurando organicidade ao trabalho das diferentes unidades que concorrem para essa formação;" (CONSELHO NACIONAL DE EDUCAÇÃO, 2015, p. 4).

O discurso da Resolução tem como interlocutor indireto os sujeitos alunos que fazem parte da esfera de formação escolar, ou seja, para quem são direcionados e justificados todos os projetos de formação educacional "atentos às características das crianças, adolescentes, jovens e adultos que justificam e instituem a vida da/e na escola, [...]" (CONSELHO NACIONAL DE EDUCAÇÃO, 2015, p. 2).

Segundo as (DCNs), cabe à escola promover "a igualdade de condições para o acesso e a permanência na escola; a liberdade de aprender, ensinar, pesquisar e divulgar a cultura, o pensamento, a arte e o saber; o pluralismo de ideias [...]" (CONSELHO NACIONAL DE EDUCAÇÃO, 2015, p. 1). Nesse contexto, a esfera de formação escolar é vista como um agente social, um 
espaço de diversidade, de democracia, de formação e informação, em que a aprendizagem de conteúdos deve facilitar a inserção do aluno nas questões sociais, no universo cultural e na formação de cidadãos capazes de atuar e conviver bem em sociedade, isto é, de promover o desenvolvimento cognitivo e a socialização dos alunos num mundo em constante evolução. Dessa forma, disseminar o conhecimento e promover a formação integral do sujeito.

O discurso do documento enuncia um momento de transição para um currículo inovador, com ricos projetos de formação, conectado a um novo modelo social, histórico e cultural, pois a formação docente deve dialogar com parâmetros contemporâneos, alinhados ao século XXI, em que a comunicação e a interação se dão de forma intensa e rápida por meio do uso dos recursos das tecnologias digitais, principalmente da internet, de modo a influenciar diretamente nossas ações e decisões.

A Resolução CNE/CP no 2/2015 dispõe, no artigo $2^{\circ}$, parágrafo $2^{\circ}$, que no exercício da docência, o profissional docente precisa ter sólida formação envolvendo o domínio e o manejo de conteúdos e metodologias, inclusive o do uso das tecnologias e inovações:

$\S 2^{\circ}$ No exercício da docência, a ação do profissional do magistério da educação básica é permeada por dimensões técnicas, políticas, éticas e estéticas por meio de sólida formação, envolvendo o domínio e manejo de conteúdos e metodologias, diversas linguagens, tecnologias e inovações, contribuindo para ampliar a visão e a atuação desse profissional. (CONSELHO NACIONAL DE EDUCAÇÃO, 2015, p. 3).

Dessa forma, "as diversas linguagens, tecnologias e inovações", estrategicamente enunciadas, reforçam o acento de valor do (CNE) para a integração das tecnologias na formação, de forma a contribuir para a ampliação dos conhecimentos, logo, então, existem o reconhecimento e solicitações das políticas públicas educacionais para que esses conhecimentos sejam contemplados e aplicados nas esferas de formações acadêmica e escolar. Em consequência disso, fica implícito que a formação profissional docente precisa proporcionar e reavaliar suas formas de ensino no nível de graduação, no 
intuito de avançar e sintonizar-se com essas novas formas de viver e conviver na sociedade da informação e do conhecimento.

O (CNE) deixa evidenciado no artigo $5^{\circ}$ da Resolução CNE/CP nº 2/2015 que a formação de profissionais do magistério deve assegurar a base comum nacional pautada pela concepção de educação como processo emancipatório e permanente, de modo a conduzir os egressos docentes ao seu desenvolvimento profissional. Assim, também aponta para o que se deve promover na formação inicial docente, inclusive sobre $\mathrm{o}$ uso das tecnologias e de dinâmicas pedagógicas:

\footnotetext{
I - à integração e interdisciplinaridade curricular, [...]

II - à construção do conhecimento, [...]

III - ao acesso às fontes nacionais e internacionais de pesquisa, ao material de apoio pedagógico de qualidade, [...]

IV - às dinâmicas pedagógicas que contribuam para o exercício profissional [...]

V - à elaboração de processos de formação do docente em consonância com as mudanças educacionais e sociais, acompanhando as transformações gnosiológicas e epistemológicas do conhecimento;

VI - ao uso competente das Tecnologias de Informação e Comunicação [...]

VII - à promoção de espaços para a reflexão crítica sobre as diferentes linguagens e seus processos de construção, [...]

VIII - à consolidação da educação inclusiva [...]

IX - à aprendizagem e ao desenvolvimento de todos(as) os(as) estudantes durante o percurso educacional por meio de currículo e atualização da prática docente que favoreçam a formação e estimulem o aprimoramento pedagógico das instituições. (CONSELHO NACIONAL DE EDUCAÇÃO, 2015, p. 6).
}

No inciso $\mathrm{V}$, deste artigo $5^{\circ}$, deixa explícito pela voz do (CNE), que as IES devem ficar atentas para promover, na construção dos (PPC), "à elaboração de processos de formação do docente em consonância com as mudanças educacionais e sociais, acompanhando as transformações gnosiológicas e epistemológicas do conhecimento;" (CONSELHO NACIONAL DE EDUCAÇÃO, 2015 , p. 6). Diante disso, há a solicitação do (CNE) para que se criem oportunidades na dinâmica curricular a fim de que o acadêmico esteja em sintonia com seu fazer docente de forma atualizada e contextualizada, conforme as mudanças engendradas na sociedade. 
No inciso VI, deste artigo 50, institui para as (IES), o compromisso institucional de que a formação conduza os egressos "ao uso competente das Tecnologias de Informação e Comunicação (TIC) para o aprimoramento da prática pedagógica e a ampliação da formação cultural dos(das) professores(as) e estudantes;" (CONSELHO NACIONAL DE EDUCAÇÃO, 2015, p. 6). Diante disso, está explícito que os projetos de formação sejam pautados na vinculação dos usos dos recursos tecnológicos, pois os autores consideram que os futuros docentes devem se apropriar dessa competência no próprio processo formativo e em sua prática docente.

No inciso VII, ainda no artigo 50, considera que a (IES), enquanto formadora, seja promotora de tempo e "espaços para a reflexão crítica sobre as diferentes linguagens e seus processos de construção, disseminação e uso" (CONSELHO NACIONAL DE EDUCAÇÃO, 2015, p. 6). Nesse contexto, as vozes do (CNE) deixam evidenciada a importância de se concederem momentos no currículo para a reflexão sobre os processos formativos que envolvem a ação docente, bem como para promover o aperfeiçoamento da consciência crítica a partir do diálogo, do confronto de ideias, de teorias e práticas que contribuam para o amadurecimento profissional, social, cognitivo, intelectual do acadêmico egresso.

O (CNE), no artigo $11^{\circ}$, assegura que a formação inicial docente requer projeto com identidade própria de curso de licenciatura e que nele sejam garantidas a flexibilização e a articulação do contexto educacional com os recursos e domínio das tecnologias. Emitindo nos incisos I, V e VII, o posicionamento axiológico das vozes do (CNE) para o uso das tecnologias e de seus recursos:

I - articulação com o contexto educacional, em suas dimensões sociais, culturais, econômicas e tecnológicas; [...]

$\mathrm{V}$ - projeto formativo que assegure aos estudantes o domínio dos conteúdos específicos da área de atuação, fundamentos e metodologias, bem como das tecnologias; [...]

VII - recursos pedagógicos como biblioteca, laboratórios, videoteca, entre outros, além de recursos de tecnologias da informação e da 
comunicação, com qualidade e quantidade, nas instituições de formação; [...]. (CONSELHO NACIONAL DE EDUCAÇÃO, 2015, p. 9).

Sob esse viés, a prática pedagógica das tecnologias digitais torna-se princípio formativo para os cursos de formação inicial docente. Sendo que, uma formação docente de qualidade depende da elaboração dos seus projetos, assim como, do percurso formativo vivenciado pelos egressos. Por isso, toda a organicidade do processo formativo e a institucionalização do uso dos recursos das tecnologias digitais na formação devem ser direcionadas no sentido de suprir as exigências atuais das políticas educacionais, e no reconhecimento dos recursos tecnológicos como apoio à prática educativa ou formativa.

Diante desse contexto, é requerida do egresso a ampliação de conceitos e de conhecimento, para que ele saiba se colocar diante das várias vozes dos sujeitos alunos, na esfera escolar, após a formação. Sendo assim, a função docente é convidada a conhecer os novos recursos tecnológicos, adaptar-se a eles, saber usá-los e compreendê-los pelo bem e evolução do processo de aprendizagem.

\section{Princípios para uma proposta de ensino com as tecnologias digitais}

Consonante com as vozes do (CNE), os cursos de formação inicial docente devem ser organizados em áreas especializadas, por componente curricular ou campo de conhecimento e/ou interdisciplinar, de forma a englobar na formação a difusão do conhecimento científico, tecnológico e educacional. Sendo assim, vejamos por meio de alguns artigos da Resolução, o que pode ser proposto para a inserção das tecnologias na formação docente:

(1) no artigo 70, parágrafo único, inciso III, a voz do (CNE) solicita que se agregue a formação a "outros ambientes culturais, científicos e tecnológicos, físicos e virtuais que ampliem as oportunidades de construção de conhecimento" (CONSELHO NACIONAL DE EDUCAÇÃO, 2015, p. 7). Dessa forma, verifica-se a solicitação de 
outros ambientes, inclusive dos tecnológicos e virtuais. Sendo assim, a utilização dos recursos de ambientes virtuais (AVA) e do ensino a distância (EAD) como apoio ao ensino-aprendizagem na formação podem e devem ser encaminhados.

(2) no artigo 70, inciso VIII, a voz do (CNE) solicita que se promovam, na formação, o "desenvolvimento, execução, acompanhamento e avaliação de projetos educacionais, incluindo o uso de tecnologias educacionais e diferentes recursos e estratégias didáticopedagógicas"; (CONSELHO NACIONAL DE EDUCAÇÃO, 2015, p. 7). Diante desse contexto, percebe-se que o futuro docente precisa aprender, desenvolver e praticar os recursos das tecnologias educacionais digitais. Sendo assim, a utilização das tecnologias educacionais digitais como recurso didático-pedagógico ou como disciplina podem e devem ser encaminhados, pois a tecnologia educacional é considerada um meio gerador de aprendizagem, uma área de conhecimento em que as tecnologias se submetem aos objetivos educacionais. Logo, a educação não pode se privar dela.

(3) no artigo $8^{\circ}$, inciso $V$, está destacado que o egresso deve ter 0 "domínio das tecnologias de informação e comunicação para o desenvolvimento da aprendizagem;" (CONSELHO NACIONAL DE EDUCAÇÃO, 2015, p. 8). Dessa forma, há o reconhecimento do $(\mathrm{CNE})$, para que a internet seja usada como fonte e apoio para o conhecimento educacional, pois a internet é considerada uma rede de infinitas possibilidades para a educação, porém, o uso desenfreado e a apropriação dos recursos midiáticos pelos alunos requerem cuidados, impõem novos desafios à formação do professor, levando-nos à reflexão sobre os percursos formativos do ensino tradicional e os do contemporâneo.

(4) no artigo $11^{\circ}$, há a solicitação do (CNE) para que se garanta nas instituições de formação a incorporação de "recursos pedagógicos 
como biblioteca, laboratórios, videoteca, entre outros, além de recursos de tecnologias da informação e da comunicação, com qualidade e quantidade, $[\ldots] "$ " (CONSELHO NACIONAL DE EDUCAÇÃO, 2015, p. 9). Dessa forma, há a solicitação de instalações físicas e o provimento dessas ferramentas que podem apoiar a formação e as diferentes ações pedagógicas.

(5) no artigo $13^{\circ}$, parágrafo $2^{\circ}$, é solicitado que os cursos de formação garantam "nos currículos conteúdos específicos da respectiva área de conhecimento ou interdisciplinares, seus fundamentos e metodologias, bem como conteúdos relacionados aos fundamentos da educação [...]" (CONSELHO NACIONAL DE EDUCAÇÃO, 2015, p. 11). Diante desse contexto, em consonância com os enunciadores, a inserção das Tecnologias Digitais ou (TICs) na grade curricular de formação pode ser encaminhada como disciplina, ou ser tratada como parte dos temas integradores de ensino ou como práticas formativas, isto é, abranger um campo específico e/ou ser usada de forma interdisciplinar. Dessa forma, as disciplinas de fundamentação teórica, além de tratarem de um saber específico, podem versar sobre outros conhecimentos, inclusive integrar os recursos das novas tecnologias para atingir os objetivos da educação. Sendo assim, as (TICs) não devem ser tratadas apenas como forma de repassar conteúdos e informações.

Dessa forma, além de saber lidar com diferentes saberes em sala de aula, o professor precisa dominar o uso das ferramentas tecnológicas, ter habilidade para integrar as tecnologias no processo ensino-aprendizagem e, assim, saber fazer escolhas conscientes e acompanhar os diferentes processos de ensino.

Sendo assim, compreende-se que a formação docente será efetiva e de qualidade, quando os interlocutores diretos da formação, entenderem o 
propósito das (DCNs), refletirem sobre suas atitudes, condutas e práticas, formar uma consciência e um forte desejo de adaptação ao campo das novidades, reconhecendo que os recursos das tecnologias digitais estão à disposição e podem ser potencialidades, isto é, se usadas de forma centrada nos objetivos educacionais como instrumentos de aprendizagem que podem revolucionar as práticas pedagógicas.

Finalizando, estamos convencidos de que tal formação não deve permanecer em descompasso com uma sociedade, a qual é marcada fortemente por comunicação, interação e muitas informações, sem haver, para isso, o preparo adequado dos futuros docentes. Convidamos os interlocutores desse discurso, o futuro docente e as (IES), para um desdobramento de olhares em relação àquilo que Ihes é instituído, tanto quanto os convidamos a imergir nas reflexões sobre a formação, as quais permanecerão ao longo do tempo. Usar tecnologias digitais e seus recursos requer preparação, mobilização, bem como colocar em ação os conhecimentos indispensáveis para tal desempenho.

\section{Considerações Finais}

Nossa investigação orientou-se pela perspectiva teórico-metodológica de Bakhtin e de seu Círculo, amparada na concepção ampla de enunciados, gêneros discursivos, esferas e dialogismo. Para tanto, dedicou-se ao estudo da constituição da Resolução CNE/CP no 2/2015 como documento oficial normativo, e dos gêneros do discurso, bem como das relações dialógicas travadas com a formação inicial docente para o uso das tecnologias digitais.

A ideia do discurso verbalizado na Resolução CNE/CP no 2/2015 está alicerçada em uma educação de qualidade cuja formação docente seja construída em bases científicas e com técnicas sólidas, capaz de promover elevado padrão acadêmico, científico, tecnológico e cultural. Destaca-se, ainda, a perspectiva de que o ensino deve estar comprometido com a democratização social e cultural, garantindo aos futuros docentes o acesso aos saberes necessários para o exercício profissional e a efetiva participação na sociedade. 
As (DCNs) correspondem a um documento oficial normativo, o que se verificou pela análise do conteúdo temático, pela forma composicional e pelo estilo. Caracteriza-se, assim, como uma espécie do gênero discursivo normativo, o qual se insere na classificação dos gêneros secundários porque possui situação comunicacional complexa e formal e tem a função de normatizar e regular os cursos de formação docente brasileiros, no nível superior.

O gênero do discurso normativo possui forma padronizada porque não comporta um estilo individual já que é um gênero extremamente estável e prescritivo. Como o destinatário do enunciado oficial é toda uma comunidade da esfera educacional, o diálogo é difuso e as relações dialógicas se estabelecem em um alto grau de distanciamento entre quem prescreve e quem recebe a orientação normativa.

A produção dessa Resolução é um consenso de vozes coletivas que criam e sustentam os discursos do documento. Assim, as principais vozes produtoras do discurso são das esferas públicas educacionais - do (MEC), do (CNE) e de seu Conselho Pleno - mas, foi possível perceber a consonância com outros interlocutores, como as vozes das (IES), dos sujeitos egressos dos cursos de formação docente, bem como as dos alunos e professores da esfera escolar. Essas, entre outras que poderiam ser suscitadas neste estudo.

O discurso da Resolução está voltado para um interlocutor direto, representado pelos diversos segmentos das Instituições de Ensino Superior (IES) e pelos profissionais responsáveis pela criação e pela gestão dos cursos de formação docente, assim como há outros interlocutores indiretos representados pelos sujeitos em formação docente, ou seja, os egressos dos cursos que fazem parte da esfera acadêmica educacional e pelos sujeitos alunos que fazem parte da esfera de formação escolar.

A partir das análises foi possível perceber que existe a preocupação, por parte do (MEC/CNE), quanto à implantação dos recursos das tecnologias digitais nos ambientes de formação docente, assim como foi possível compreender a responsabilidade da formulação de projetos pedagógicos e 
currículos pelas (IES) com propostas curriculares que, de fato, cumpram o que propõem as (DCNs).

Os aspectos levantados e analisados no contexto das (DCNs) ratificam a nossa hipótese inicial, de que há a necessidade de pensar e planejar novos rumos para a formulação de práticas pedagógicas inovadoras, isto é, em consonância com as realidades em constante evolução para o uso das tecnologias digitais nos ambientes de formação acadêmica e escolar.

\section{Referências}

BAKHTIN, Mikhail Mikhailovich. Estética da criação verbal. Tradução de Paulo Bezerra. 6. ed. São Paulo: Editora WMF: Martins Fontes, 2011.

BRAIT, Beth (org.). Bakhtin: outros conceitos-chave. 2. ed. São Paulo: Contexto, 2016.

BRAIT, Beth. Bakhtin e a natureza constitutivamente dialógica da linguagem. In: BRAIT, Beth (org.). Bakhtin, dialogismo e construção de sentido. Campinas: UNICAMP, 2005. p. 87-98.

CONSELHO NACIONAL DE EDUCAÇÃO. Resolução CNE/CP no 02, de 01 de julho de 2015. Diretrizes Curriculares Nacionais para a formação inicial em nível superior e para a formação continuada. Brasília, DF: MEC/CNE, 2015. Disponível em:

http://portal.mec.gov.br/index.php?option=com_docman\&view=download\&alia s=17719-res-cne-cp-002-03072015\&category_slug=julho-2015pdf\&Itemid=30192. Acesso em: 25 out. 2018.

CURY, Carlos Roberto Jamil. Conselhos de Educação: fundamentos e funções. Revista Brasileira de Política e Administração da Educação, Porto Alegre, RS, v. 22, n. 1, p. 41-67, 2006. Disponível em: http://seer.ufrgs.br/index.php/rbpae/article/view/18721/10944. Acesso em: 9 de julho de 2018.

FARACO, Carlos Alberto. Linguagem e diálogo: as ideias linguísticas do círculo de Bakhtin. São Paulo: Parábola, 2009.

FIORIN, José Luiz. Introdução ao pensamento de Bakhtin. 2. ed. São Paulo: Contexto, 2017.

GRILLO, Sheila Vieira de Camargo. Esfera e campo. In: Bakhtin: outros conceitos-chave. 2. ed. São Paulo: Contexto, 2016. p. 133-160. 
O consenso entre as vozes dialógicas das DCNs para o uso das tecnologias digitais na formação docente

MARCHEZAN, Renata Coelho. Diálogo. In: BRAIT, B. (org.). Bakhtin: outros conceitos-chave. 4. ed. São Paulo: Contexto, 2016. p. 115-131.

RESOLUÇÃO. In: FERREIRA, Aurélio Buarque de Holanda. Dicionário Aurélio básico da língua portuguesa. Rio de Janeiro: Nova Fronteira, 1988. p. 566. 